\title{
Infraestructure to support biomedical applications
}

Francisco Abel Cedrón Santaeufemia 


\section{De donde sale}

- BioCAl surge del proyecto Red Gallega de Investigación Biomédica en el año 2008

- Se identifica un clarísimo potencial de la investigación en Galicia para la investigación en biomedicina.

- Limitada por el procesado de los datos

- Por lo que se solicita un proyecto al ministerio (Resolución definitiva en 2012)

- Creación de un cluster dedicado a la investigación en biomedicina 


\section{Usos}

- Análisis de secuenciación de moléculas

- Análisis de proteínas

- Análisis de interacciones complejas basadas en potenciales

- Docking

- Virtual Screening

- Aplicación de técnicas de Computación Evolutiva y redes neuronales en el desarrollo e identificación de fármacos o enfermedades

- Etc... 


\section{Needleman-Wunsch}

- Es un algoritmo que sirve para analizar las similaridades y diferencias entre dos secuencias

- El objetivo del algoritmo es alinear dos cadenas

- $\mathrm{s} 1$ = GAATTCAGTTA

- $\mathrm{s} 2$ = GGATCGA

El alineamiento sería

GAATTCAGTTA

GGAT-C-G--A 


\section{Needleman-Wunsch}

\begin{tabular}{|c|c|c|c|c|c|c|c|c|c|c|c|c|}
\hline & & $\mathrm{A}$ & $\mathrm{G}$ & $\mathrm{A}$ & $\mathrm{C}$ & $\mathrm{T}$ & $\mathrm{A}$ & $\mathrm{G}$ & $\mathrm{T}$ & $\mathrm{T}$ & $\mathrm{A}$ & $\mathrm{C}$ \\
\hline & 0 & -5 & -10 & -15 & -20 & -25 & -30 & -35 & -40 & -45 & -50 & -55 \\
\hline $\mathrm{C}$ & -5 & -3 & -8 & -13 & -6 & -11 & -16 & -21 & -26 & -31 & -36 & -41 \\
\hline $\mathrm{G}$ & -10 & -6 & 4 & -1 & -6 & -9 & -12 & -9 & -14 & -19 & -24 & -29 \\
\hline $\mathrm{A}$ & -15 & 0 & -1 & 14 & 9 & 4 & 1 & -4 & -9 & -14 & -9 & -14 \\
\hline $\mathrm{G}$ & -20 & -5 & 7 & 9 & 9 & 6 & 3 & 8 & 3 & -2 & -7 & -12 \\
\hline $\mathrm{A}$ & -25 & -10 & 2 & 17 & 12 & 7 & 16 & 11 & 6 & 1 & 8 & 3 \\
\hline $\mathrm{C}$ & -30 & -15 & -3 & 12 & 26 & 21 & 16 & 11 & 11 & 6 & 3 & 17 \\
\hline $\mathrm{G}$ & -35 & -20 & -8 & 7 & 21 & 23 & 20 & 23 & 18 & 13 & 8 & 12 \\
\hline $\mathrm{T}$ & -40 & -25 & -13 & 2 & 16 & 29 & 24 & 19 & 31 & 26 & 21 & 16 \\
\hline
\end{tabular}


Needleman-Wunsch

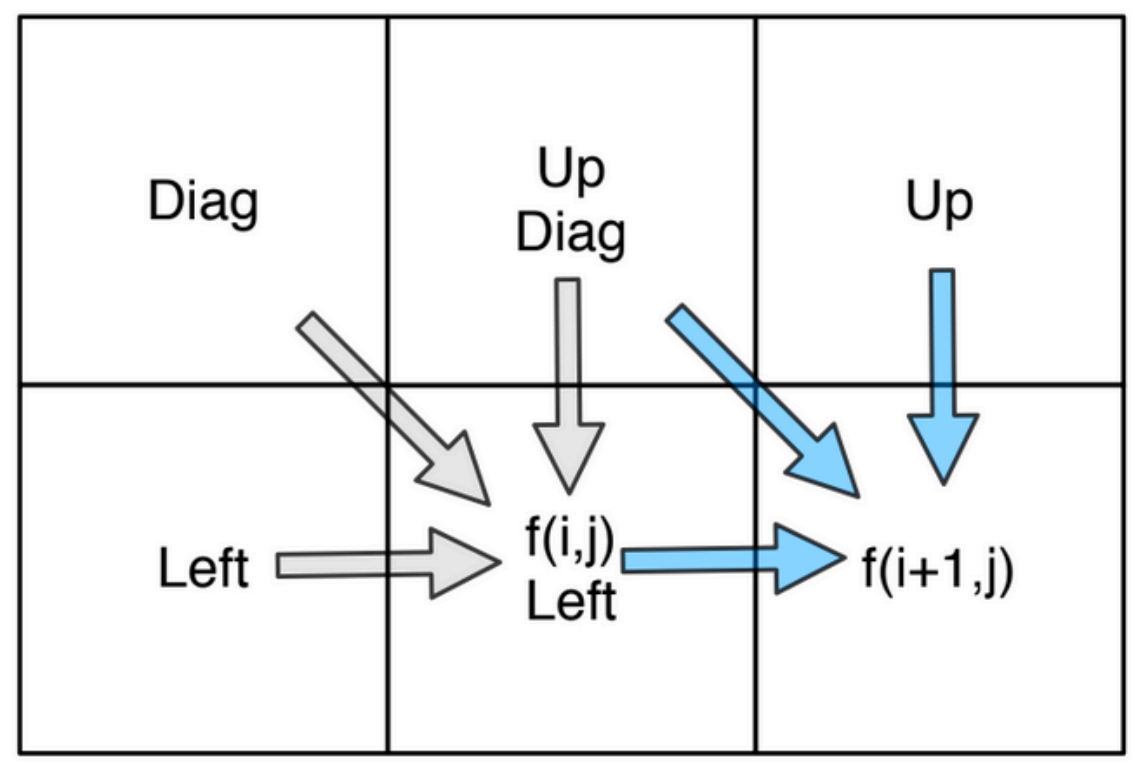




\section{Needleman-Wunsch}

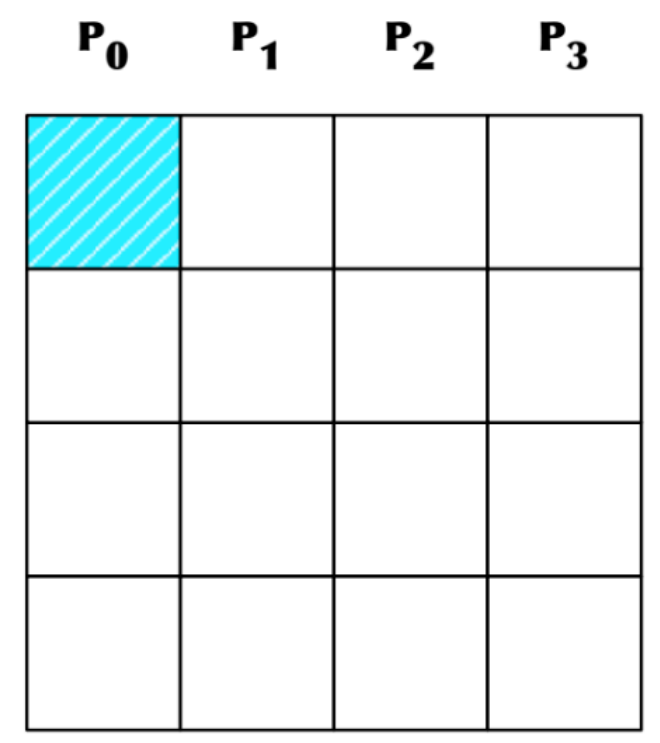

Instante 1

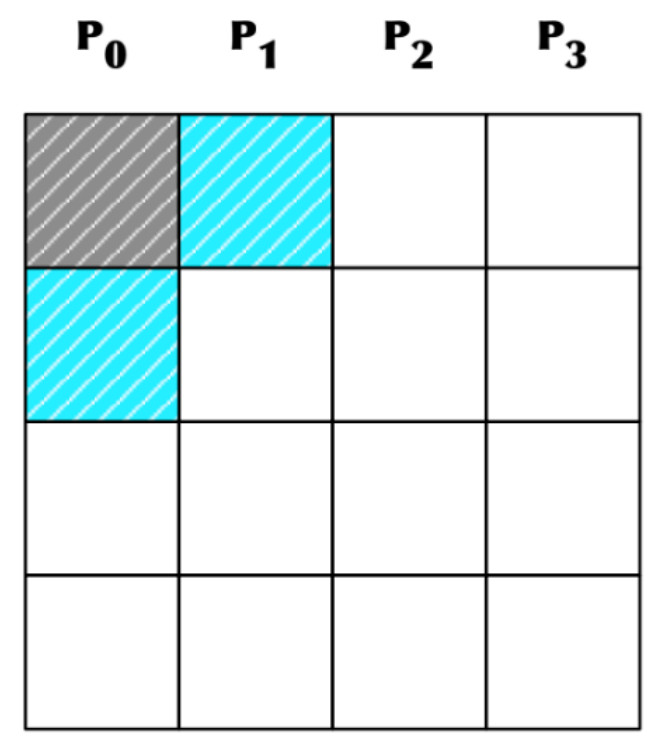

Instante 2

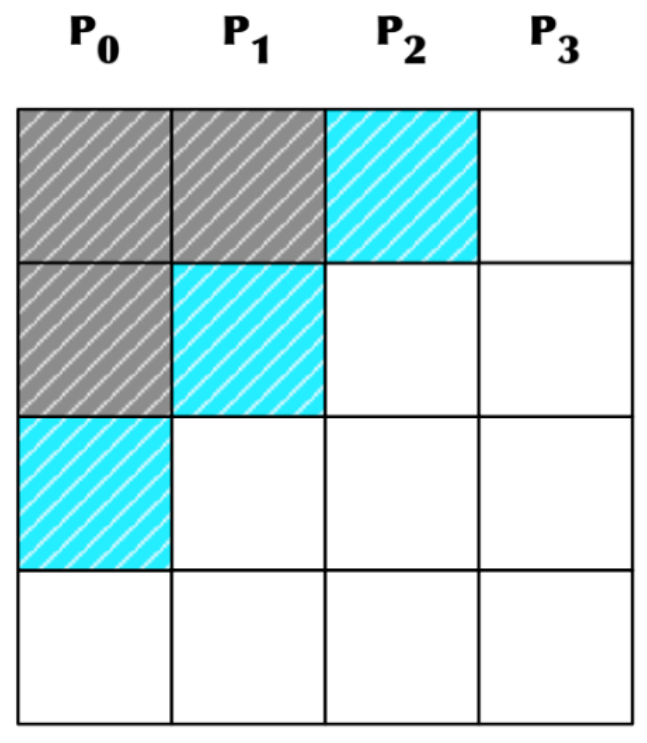

Instante 3 


\section{Needleman-Wunsch}

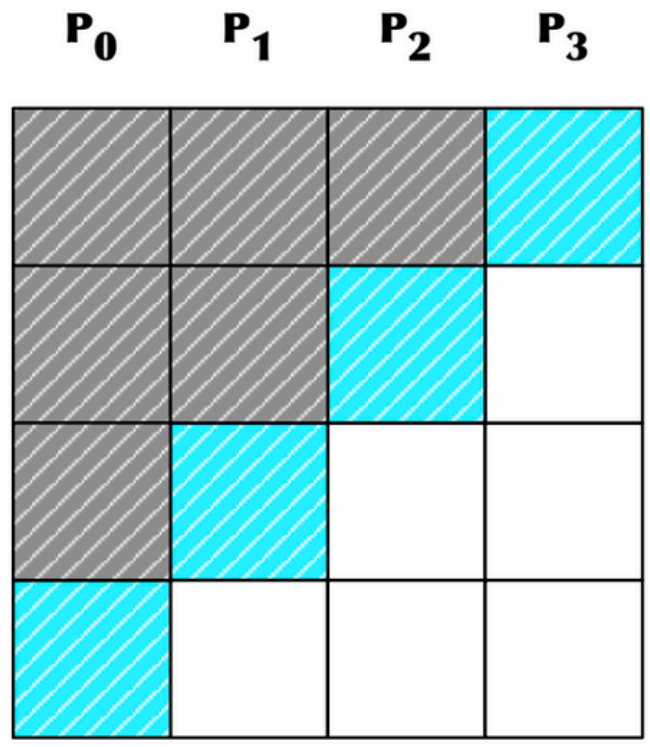

Instante 4

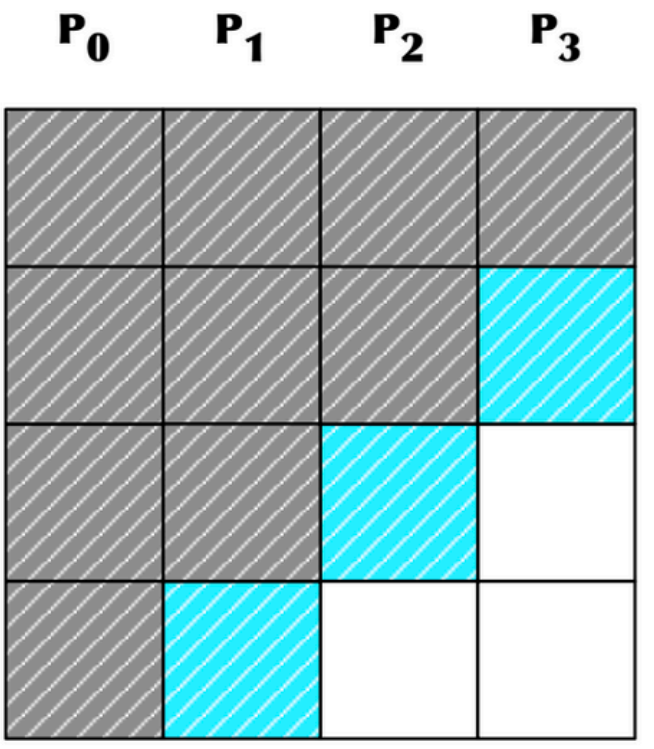

Instante 5
$\begin{array}{llll}\mathbf{P}_{\mathbf{0}} & \mathbf{P}_{\mathbf{1}} & \mathbf{P}_{2} & \mathbf{P}_{\mathbf{3}}\end{array}$

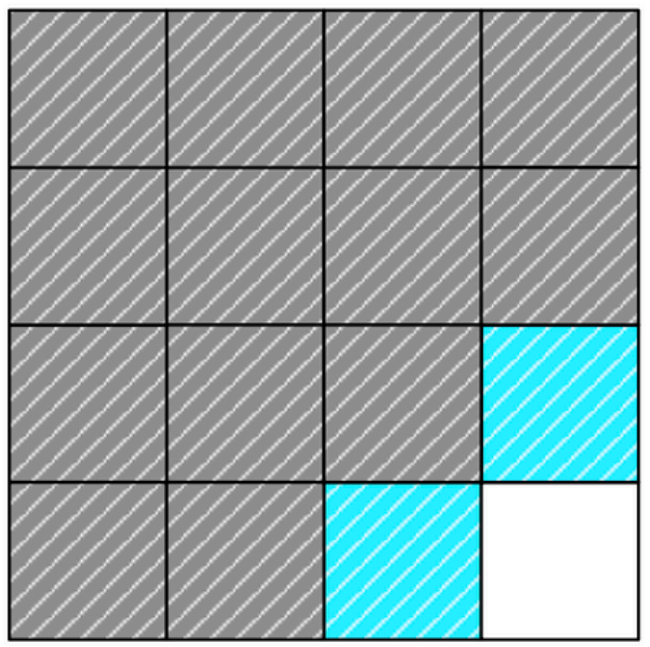

Instante 6 
Needleman-Wunsch

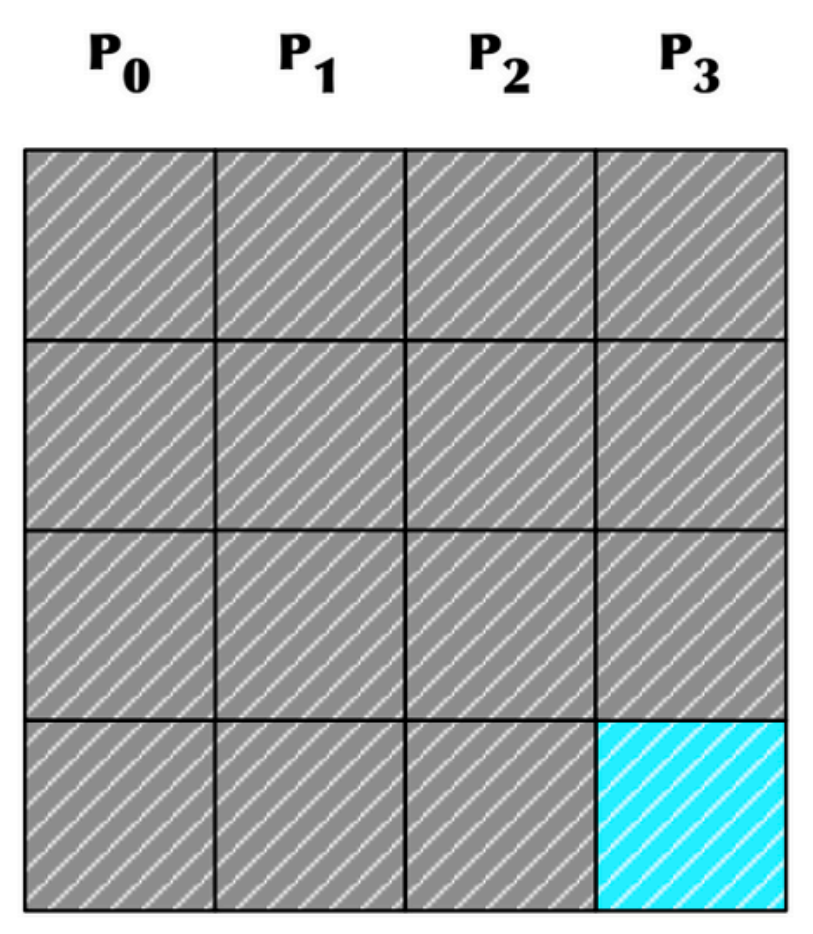

Instante 7

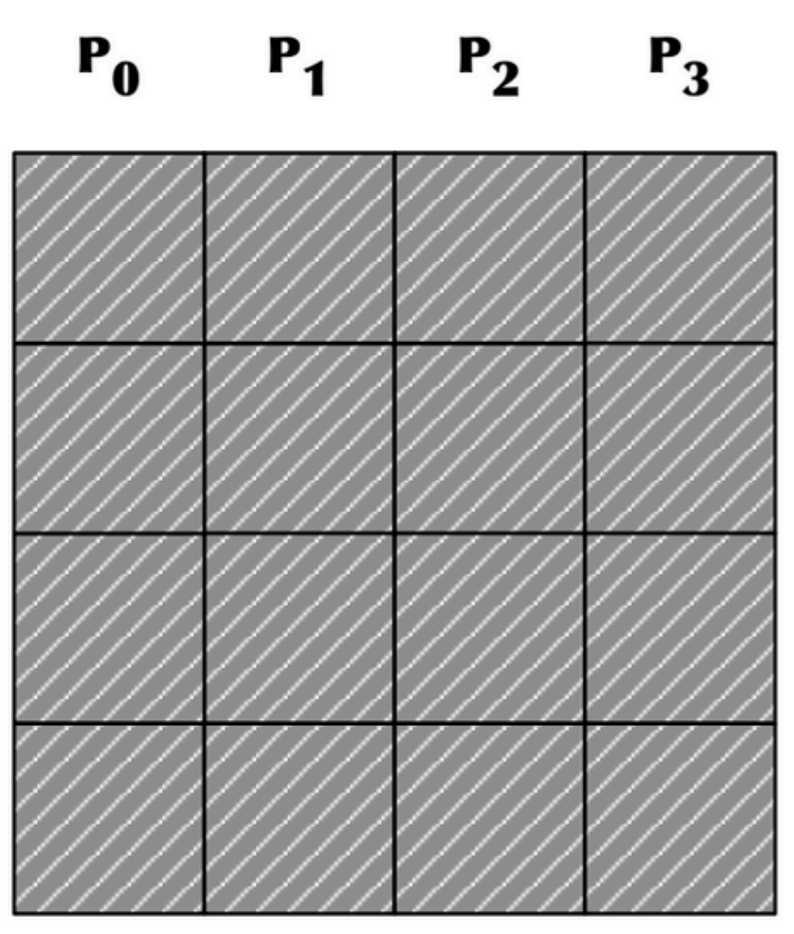

Instante 8 


\section{Needleman-Wunsch}

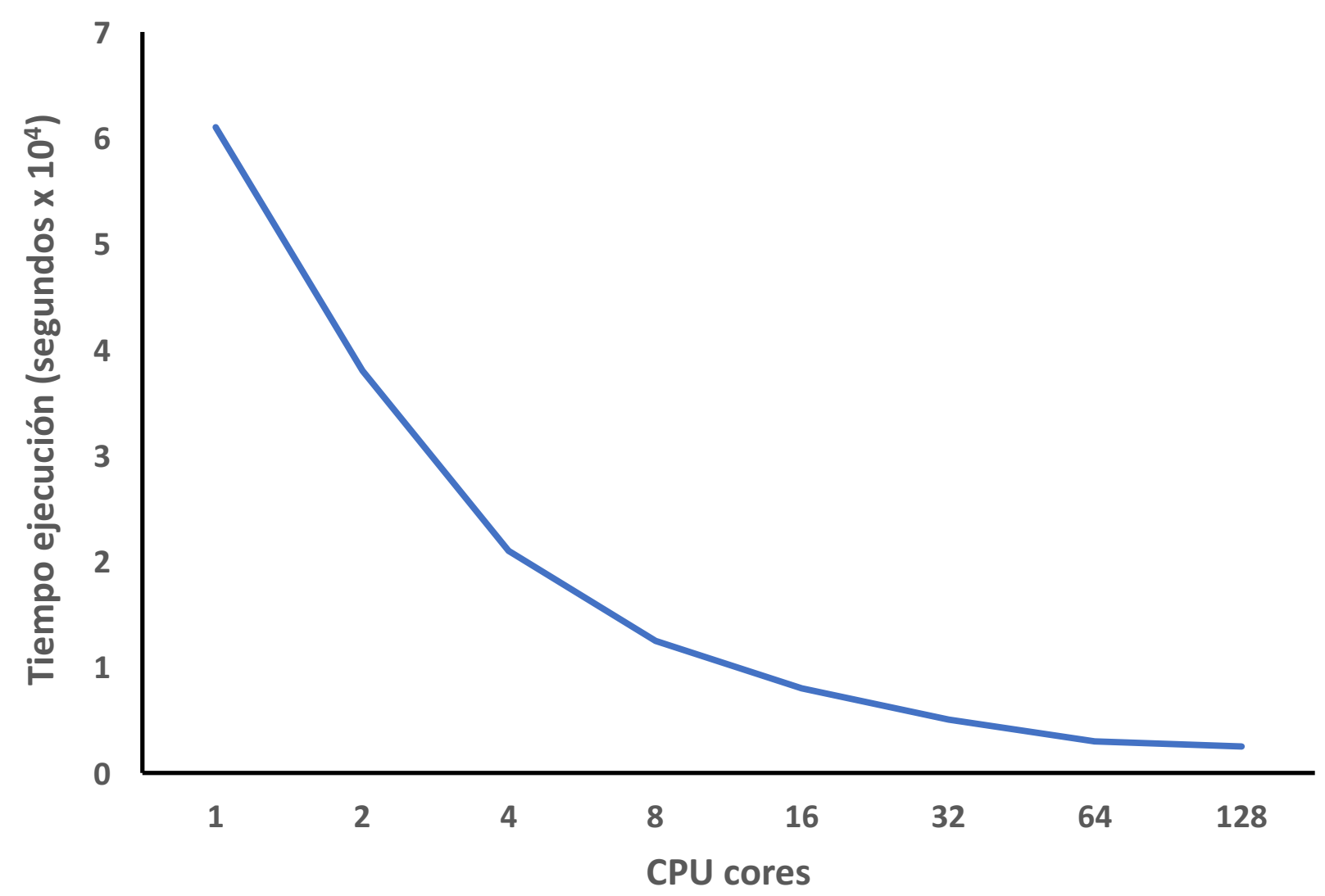




\section{Escalado de imágenes}
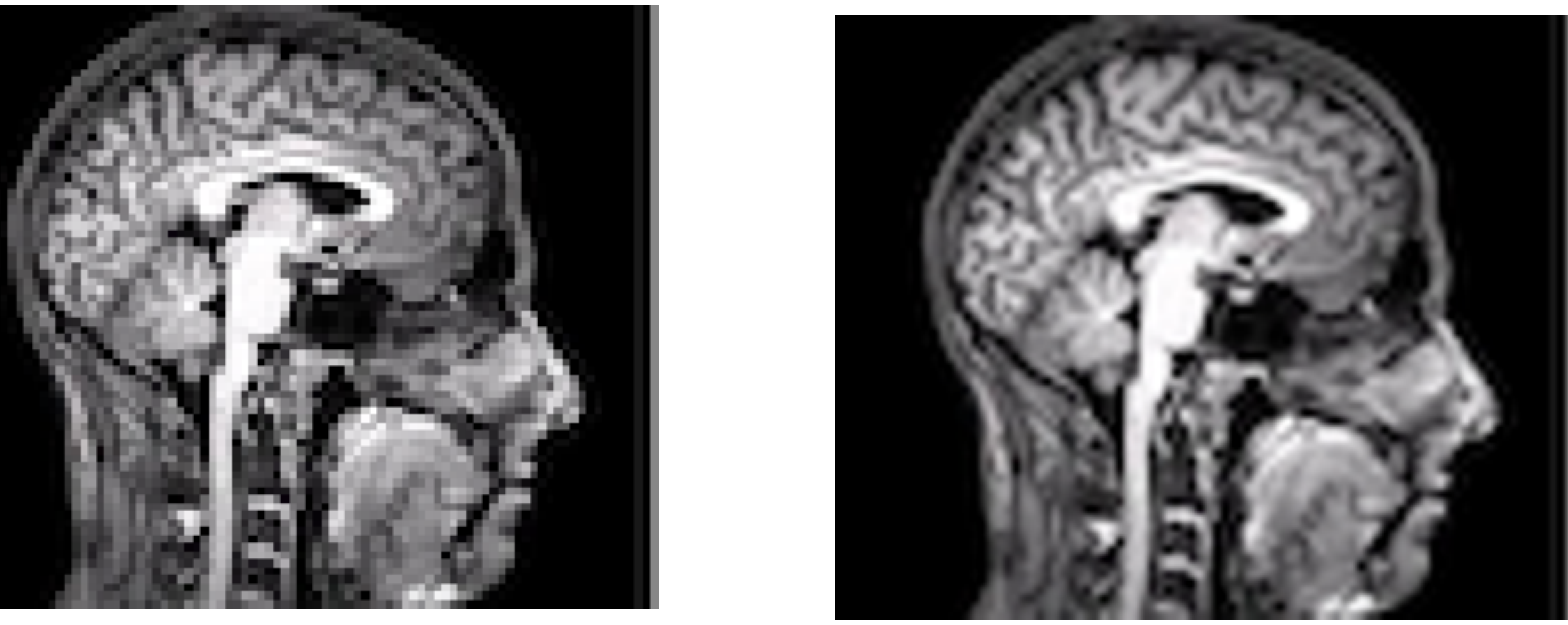


\section{Escalado de imágenes}

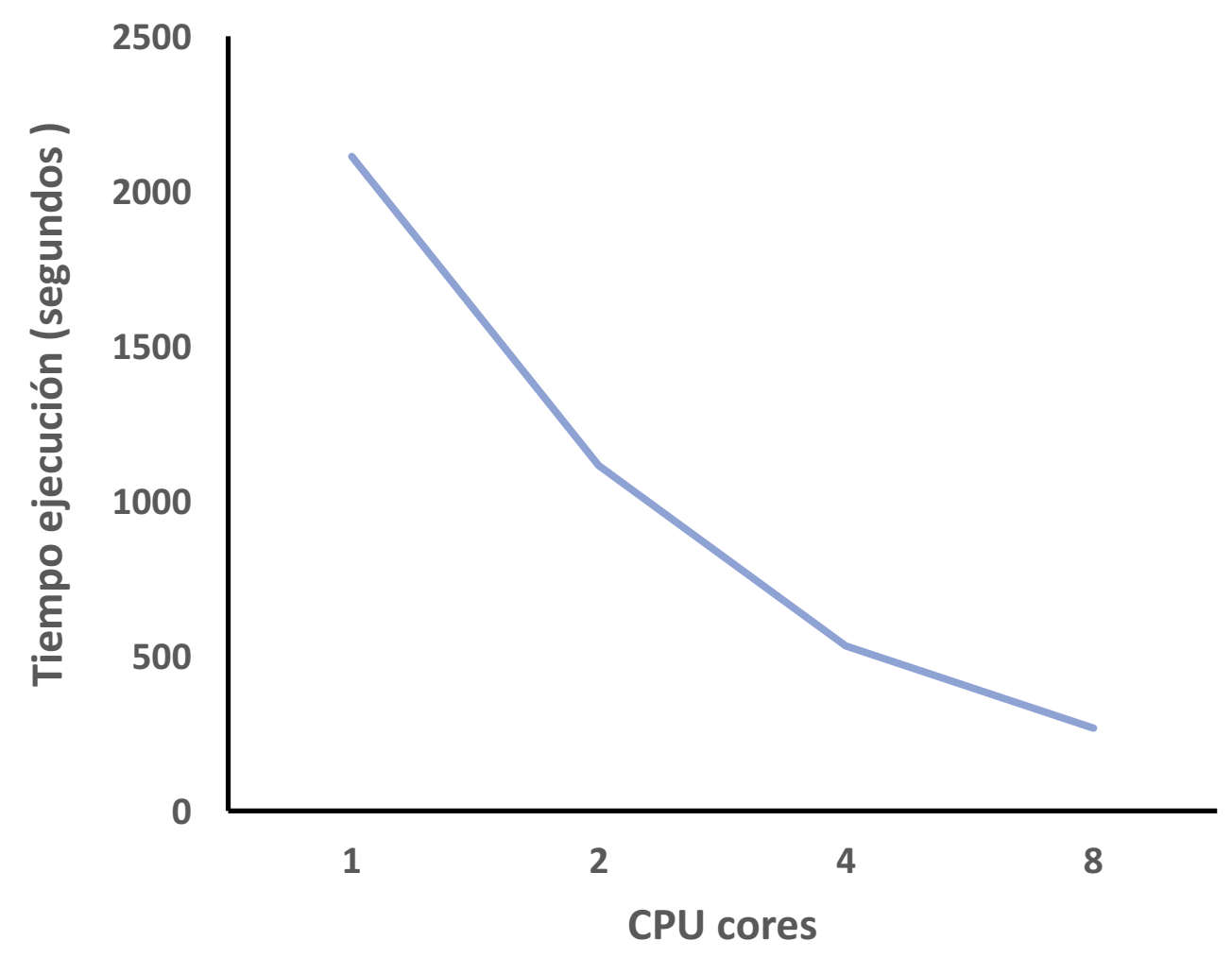




\section{Características}

- Información técnica

- 200 cores de cómputo

- Interconexión a $56 \mathrm{~Gb} / \mathrm{s}$

- 40 TB de almacenamiento

- Software adaptado para HPC

- SLURM

- Instalación por módulos 


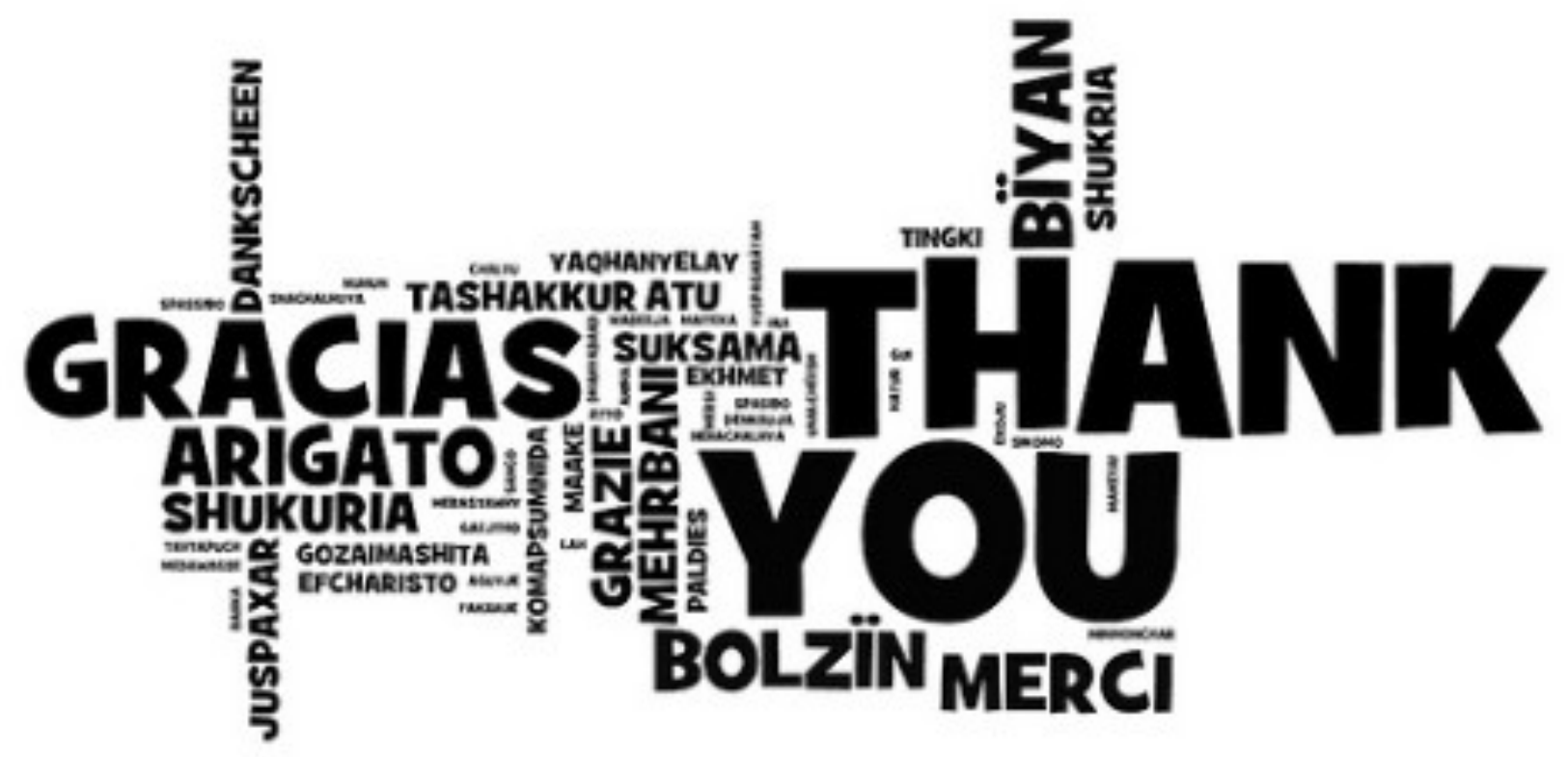

